\title{
Acute effect of low dose theophylline on the circulatory disturbances of cirrhosis
}

\author{
E H Forrest, I A D Bouchier, P C Hayes
}

\begin{abstract}
Background-Adenosine is a potent vasoactive substance that may be responsible for mediating the altered haemodynamics found in patients with cirrhosis.

Aim-The administration of oral theophylline was used to investigate the effect of adenosine receptor antagonism upon the circulation of patients with cirrhosis.

Methods-Twenty eight patients were given oral theophylline and intravascular haemodynamic measurements obtained over approximately one hour.

Results-After $240 \mathrm{mg}$ of oral theophylline elixir the hepatic venous pressure gradient mean fell from $21.8(2 \cdot 1)$ to 19.9 (2.4) $\mathrm{mm} \mathrm{Hg}$ (p<0.01), and azygos blood flow fell from 481 (94) to $375(83) \mathrm{ml} / \mathrm{min}$ $(p<0.05)$. There were no changes in cardiac output or systemic vascular resistance despite a fall in mean arterial pressure $(92.2(2.0)$ to $89.2(1.8) \mathrm{mm} \mathrm{Hg}$; $\mathrm{p}<0.05)$ and a rise in heart rate $(78.3(3.0)$ to $82.4(3.2) ; p<0 \cdot 001)$. Left renal vein flow measured by a reverse thermodilution catheter rose from $387(91)$ to $601(119) \mathrm{ml}$ $\mathrm{min}(\mathrm{p}<0 \cdot 05)$. The proportion of cardiac output perfusing the left kidney rose from $5 \cdot 0(1 \cdot 3)$ to $9 \cdot 7(2 \cdot 8) \%$.
\end{abstract}

Conclusions-These changes indicate a significant role for adenosine in the renal vasoconstriction and a more minor role in the maintenance of portal hypertension.

(Gut 1997; 40: 139-144)

Keywords: theophylline, adenosine, cirrhosis, portal hypertension, renal circulation.

The circulatory disturbances associated with cirrhosis are the cause of many of the complications of this condition. Some of these changes are paradoxical: portal hypertension is found together with systemic hypotension and peripheral vasodilatation, but with renal vasoconstriction. Thus a unifying hypothesis concerning their aetiology is not obvious.

Most hypotheses suggest that a circulating or a locally produced vasoactive substance(s) is responsible for the hyporesponsiveness of vascular tissue to vasopressor stimuli. The resulting vasodilatation contributes to the 'forward' component of portal hypertension as well as producing the typical hyperdynamic circulation of cirrhosis with its low systemic vascular resistance and high cardiac output. By the peripheral vasodilatation hypothesis, the reduction in effective circulating plasma volume stimulates renal vasoconstriction and sodium retention. ${ }^{1}$

Among putative mediators of the vasodilatation are glucagon, prostacyclin, vasoactive intestinal peptide, and most recently nitric oxide. ${ }^{2}{ }^{3}$ However none has yet been demonstrated to be solely responsible for the changes seen. A drawback of ascribing a purely vasodilating substance to account for these changes is that it would not explain why the renal circulation is exempt from the hyporesponsiveness to vasoconstrictors seen elsewhere in the vascular tree. It is perhaps more likely that there is an imbalance of locally produced vasoactive substances, which modify regional vascular response to systemic stimuli.

Adenosine is one such substance. It is produced locally often in response to tissue hypoxia and acts to reduce local oxygen utilisation. ${ }^{4}$ Systematically it acts through adenosine-2 receptors that predominantly vasodilate. Indeed this is the basis of the hepatic artery buffer response, mediated by adenosine, which regulates total liver blood flow. ${ }^{5}$ However in the kidney it vasoconstricts afferent arterioles through adenosine-1 receptors, dilates efferent arterioles, and redistributes blood from the renal cortex to the medulla. ${ }^{67}$

Studies in animal models of cirrhosis have shown differing effects of non-specific adenosine receptor blockade upon the splanchnic circulation. ${ }^{89}$ No beneficial effect was seen on the portal circulation in one study of patients with cirrhosis. ${ }^{10}$ However in patients with cirrhosis intravenous theophylline and aminophylline have been shown to have beneficial effects on the systemic and renal circulations respectively. ${ }^{11} 12$ Theophylline is a non-specific adenosine antagonist, ${ }^{13}$ but this may only be evident at low concentrations in the plasma as at higher concentrations phosphodiesterase inhibition may mediate its actions. ${ }^{14}$

The purpose of this study was to assess the circulatory effects of low plasma concentrations of theophylline after oral administration, to assess the role of adenosine in the haemodynamics of patients with cirrhosis.

\section{Methods}

A total of 28 patients with biopsy confirmed cirrhosis were studied. None of the patients had received vasoactive medication within 72 hours of the study and patients were fasted for 12 hours. Caffeine containing beverages were avoided for 24 hours before the study. Each study assessed the effect after $240 \mathrm{mg}$ oral theophylline elixir (Neulin Liquid, 3M Health 
Care Ltd) over a one hour period. Patients were studied in the supine position and an 8.5 FG introducer (Baxter Healthcare Corporation, USA) was inserted into the right femoral vein after local infiltration with $2 \%$ lignocaine. The vascular catheters were positioned under fluoroscopic control.

All patients gave informed consent and the study was approved by the Lothian Medicine and Oncology Ethics Committee.

\section{Assessment of the portal circulation}

Through the introducer a Sidewinder II torque balloon catheter (Cordis Corporation, USA) was positioned in the right hepatic veins of 18 patients. Free and wedged hepatic venous pressures (FHVP and WHVP) were recorded. Hepatic venous pressure gradient (HVPG) was calculated as WHVP minus FHVP. In six of these patients hepatic blood flow (HBF) was also calculated by the indocyanine green (ICG) method. ${ }^{15}$ An intravenous infusion of $0.2 \mathrm{mg} / \mathrm{min}$ of ICG was commenced after a bolus of $10 \mathrm{mg}$. An equilibration period of 40 minutes was allowed before three blood samples at two minute intervals were taken simultaneously from the right hepatic vein and the right femoral vein each. Patients with an ICG extraction of $<10 \%$ were excluded from the analysis. $\mathrm{HBF}$ was calculated as follows:

\section{$\mathrm{HBF}=(\mathrm{ICG}$ clearance/ICG extraction $) /$ (1-haematocrit)}

Hepatic vascular resistance (HVR) was calculated as follows:

\section{HVR=79.96 (WHVP-FHVP)/HBF}

All hepatic vein measurements were made at baseline and 60 minutes after theophylline administration.

Azygos blood flow (AzBF) was measured in 11 of these patients. A double thermistor catheter (Webster Laboratories, California) was positioned in the azygos vein. Its position remained constant throughout the study. The thermistor signals were transferred through a custom built interface (B55724 type CF) and processed in an IBM model PS2-286 microcomputer system as described previously. ${ }^{16}$ Mean blood flows were recorded over a $30-40$ second period. Recordings were made before and 30 and 60 minutes after theophylline administration. Previous studies have shown that theophylline levels peak in patients with cirrhosis at this time after oral administration. ${ }^{17}$

A control group was not used in the study of the portal circulation as it has been established that these haemodynamic parameters are constant during such studies.

\section{Assessment of the systemic and pulmonary} circulations

Automatic heart rate (HR) and blood pressure recordings ( $A+D$ Company, model UA-743) were at 10 minute intervals throughout each study.
Through the right femoral vein introducer a Swan-Ganz catheter (Baxter Healthcare Corporation) was positioned in the right pulmonary artery after measurement of RAP in 10 patients. Pulmonary artery pressure (PAP) and pulmonary capillary wedged pressure (PCWP) were measured directly. Cardiac output (CO) was measured by the thermodilution technique. Systemic vascular resistance (SVR) was calculated as:

$$
\text { SVR=79.96 (MAP-RAP)/CO }
$$

where mean arterial pressure (MAP) is:

$$
\begin{aligned}
\mathrm{MAP}= & (\text { pulse pressure } / 3) \\
& + \text { diastolic blood pressure }
\end{aligned}
$$

Pulmonary vascular resistance (PVR) was calculated as:

\section{PVR=79.96 (PAP-PCWP)/CO}

Measurements were made at baseline and immediately after the final renal vein flow measurement.

\section{Assessment of the renal circulation}

Through the right femoral vein introducer a verse thermodilution catheter was positioned in the left renal vein of 10 patients after cardiac output studies had been carried out. Its position remained constant throughout the study. Renal vein blood flow (RVF) was recorded in a similar manner to that of AzBF. Recordings were made before and 30 and 60 minutes after theophylline administration in 10 patients. In four additional patients RVF and CO measurements were taken and used as controls without theophylline administration. Recordings were made at the same time points.

Only one intravenous introducer was inserted in any one patient, and so only one catheter was in position at any one time. In all patients the reverse thermodilution catheter was kept in same position throughout the course of the study. After the 60 minute study period the Swan-Ganz catheter or the hepatic venous catheter, or both, were repositioned to obtain final measurements. These final recordings were made within 10 minutes of the reverse thermodilution catheter removal.

\section{Theophylline and caffeine measurement}

Theophylline and caffeine were measured by high performance liquid chromatography using a modified method to that already described. ${ }^{18}$ Blood was collected into tubes containing $5 \%$ EDTA. A Waters NOVA-PAK C18 column $(250 \mathrm{~mm} \times 4.6 \mathrm{~mm})$ was used. Twenty $\mu 1$ of plasma was loaded onto the column with a flow rate of $1 \mathrm{ml} / \mathrm{min}$. Detection was at $275 \mathrm{~nm}$ (Perkin Fulmer Diode Array Detector).

\section{Statistical analysis}

Results are expressed as mean (SEM). For parametric data paired Student's $t$ test and Pearson's correlation were used. Wilcoxon signed ranked test and Spearman's correlation were used for non-parametric variables (RVF and HBF). 


\section{Results}

\section{Patients studied}

The mean age of theophylline treated patients was 57 years (range 41-70). Mean Child's score was nine $(6 \mathrm{~A}, 11 \mathrm{~B}, 7 \mathrm{C})$. Fourteen patients had ascites and 19 had oesophageal varices. The four control patients had a mean Child's score of 11 (2B, 2C). All four had ascites or oesophageal varices, or both.

All patients tolerated the theophylline well without side effects.

Effects on portal haemodynamics

There was a significant, although variable fall in HVPG $(21.8(2 \cdot 1)$ to $19.9(2 \cdot 4) \mathrm{mm} \mathrm{Hg}$; $\mathrm{p}<0.01$ ), accounted for by reductions in the

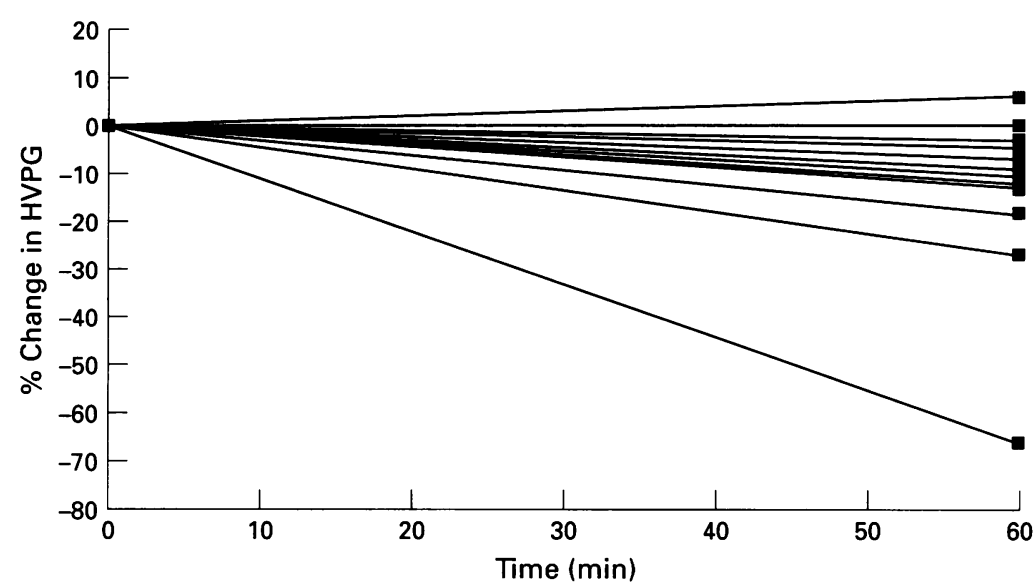

Figure 1: Percentage change in HVPG after theophylline.

TABLE I Effect of theophylline on portal haemodynamics

\begin{tabular}{lrcc}
\hline & Number & \multicolumn{1}{c}{ Baseline } & 60 minutes \\
\hline FHVP (mm Hg) & 18 & $2 \cdot 4(0 \cdot 8)$ & $2 \cdot 4(0 \cdot 7)$ \\
WHVP (mm Hg) & 18 & $24 \cdot 1(2 \cdot 3)$ & $22 \cdot 4(2 \cdot 5)^{\star \star}$ \\
HVPG (mm Hg) & 18 & $21 \cdot 8(2 \cdot 1)$ & $19 \cdot 9(2 \cdot 4)^{\star \star}$ \\
HBF (ml/min) & 6 & $1377(428)$ & $1268(141)$ \\
HVR (dynes-s/cm ${ }^{-5}$ ) & 6 & $7804(2138)$ & $6195(999)$ \\
AzBF (ml/min) & 11 & $481(94)$ & $375(83)$ \\
\hline
\end{tabular}

Mean $(\mathrm{SEM}) ;{ }^{\star \star} \mathrm{p}<0.01$ compared with baseline.

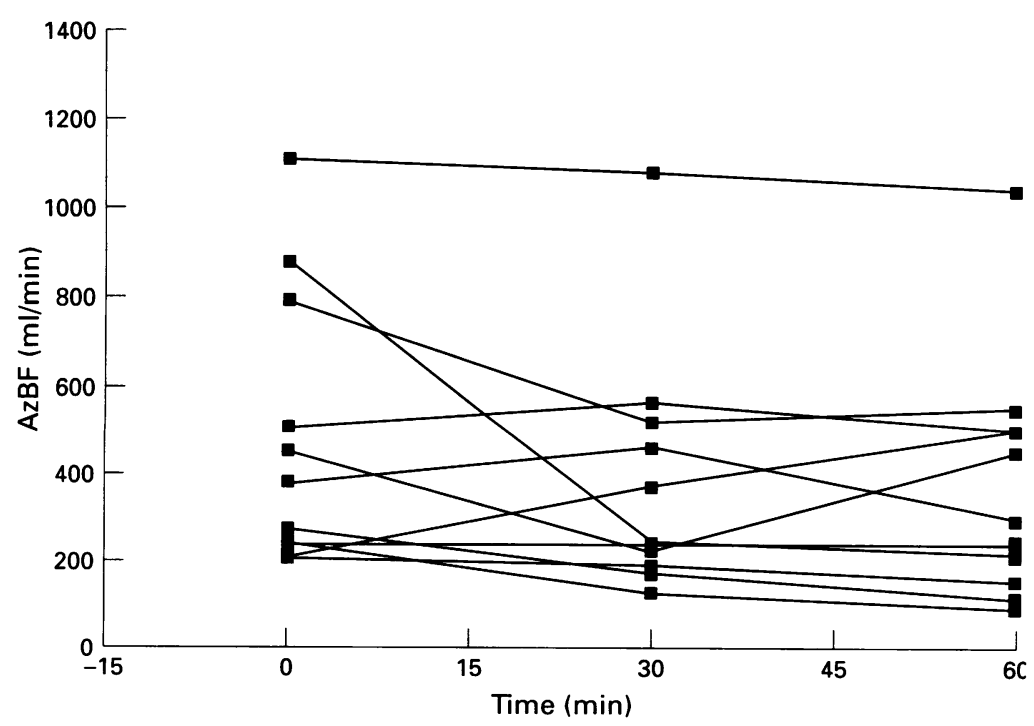

Figure 2: Effect of theophylline on azygos blood flow.
WHVP $(24 \cdot 1(2 \cdot 3)$ to $22.4(2 \cdot 5) \mathrm{mm} \mathrm{Hg}$; $\mathrm{p}<0.01)$. However the mean fall in HVPG was only $10 \cdot 4(4 \cdot 1) \%$ with only $35 \%$ of the patients having falls greater than $10 \%$ (Fig 1). No significant change in HBF was seen (Table I). However there was a significant reduction in AzBF from 481 (94) to 375 (83) $\mathrm{ml} / \mathrm{min}$ (Fig 2). A reduction was seen in all but one patient and the change in AzBF correlated with the rise in plasma theophylline after one hour $(r=0.699, \mathrm{p}<0.05)$.

\section{Effects on systemic and pulmonary} haemodynamics

There was a statistically significant rise in HR, and a fall in MAP. There were no changes in CO or SVR (Table II). Changes in portal haemodynamic variables did not correlate with any change in $\mathrm{CO}$. However there were significant falls in PAP and PVR.

\section{Effects on renal haemodynamics}

The RVF rose from $387(91)$ to 601 (119) ml/ min $(p<0.05)$ (Figs 3 and 4$)$. This rise was significant 30 and 60 minutes after theophylline administration. After one hour the mean rise in RVF was 72 (28)\% (Fig 5). The percentage of $\mathrm{CO}$ perfusing the left kidney at baseline was $5.0(1.3) \%$. One hour after theophylline administration it rose to $9 \cdot 7(2 \cdot 8) \%$ $(p<0.05)$. Six of 10 patients studied had ascites and these patients tended to have lesser rises in $\mathrm{RBF}$ in response to theophylline (119 (69) in comparison with $356(132) \mathrm{ml} / \mathrm{min}$ in those without ascites). The control subjects showed no significant change in RVF or systemic haemodynamics (Table III).

The haemodynamic responses to theophylline did not vary with the severity of liver disease as determined by Childs-Pugh grade.

\section{Methyl xanthine values}

The plasma concentrations of theophylline and caffeine are shown in Table IV. Baseline caffeine value correlated with prothrombin time $(r=0 \cdot 717, \mathrm{p}<0.001)$.

\section{Discussion}

The cause of the circulatory disturbances of cirrhosis remains elusive. The systemic vasodilatation may be due in part to excessive nitric oxide production, but portal hypertension does not seem to be affected by nitric oxide synthase inhibition. ${ }^{19}$ The vascular reactivity of the renal circulation seems to be different to that elsewhere in the body. Whereas systemic and splanchnic vessels are hyporeactive to a variety of endogenous vasoconstrictors ${ }^{20-22}$ renal blood flow correlates well with plasma noradrenaline values. ${ }^{23}$

Adenosine is formed from the degradation of ATP by 5'-nucleotidase often in response to local tissue hypoxia. It modifies local vascular responses to systemically acting vasoactive substances. In the hepatic artery adenosine may inhibit the vasoconstrictor action of 
TABLE II Effect of theophylline on systemic, renal, and pulmonary haemodynamics

\begin{tabular}{llccc}
\hline & Number & Baseline & 30 minutes & 60 minutes \\
\hline HR (bpm) & 24 & $78 \cdot 3(3 \cdot 0)$ & $83(3 \cdot 8)$ & $82 \cdot 4(3 \cdot 2)^{\star \star \star}$ \\
MAP (mm Hg) & 24 & $92 \cdot 2(2 \cdot 0)$ & $91 \cdot 1(2 \cdot 2)$ & $89 \cdot 2(1 \cdot 8)^{\star}$ \\
CO (1/min) & 10 & $7 \cdot 22(0 \cdot 76)$ & - & $7 \cdot 15(0 \cdot 70)$ \\
SVR (dynes-s/cm & -5 & $1149(139)$ \\
PAP $(\mathrm{mm} \mathrm{Hg})$ & 10 & $1179(152)$ & - & $8 \cdot 1(1 \cdot 8) \dagger$ \\
PCWP (mm Hg) & 10 & $11 \cdot 2(2 \cdot 2)$ & - & $4 \cdot 0(1 \cdot 6)$ \\
PVR (dynes-s/cm & 10 & $4 \cdot 3(1 \cdot 6)$ & - & $45(7) \dagger$ \\
RVF (ml/min) & 10 & $82(11)$ & - & $601(119)^{\star}$ \\
\hline
\end{tabular}

Mean $(\mathrm{SEM}) ; \dagger \mathrm{p}<0.005,{ }^{\star \star \star} \mathrm{p}<0.001,{ }^{\star} \mathrm{p}<0.05$ compared with baseline.

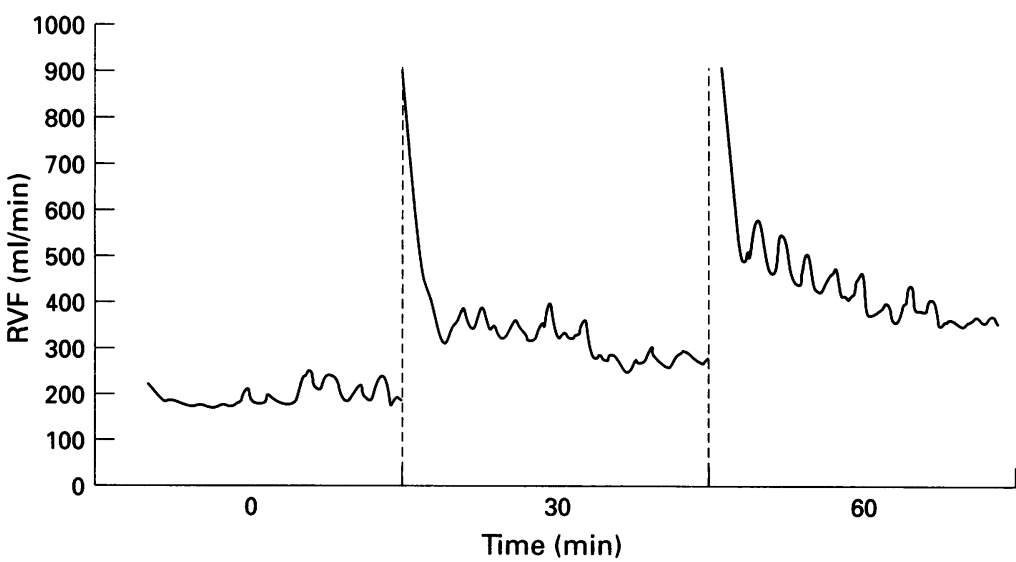

Figure 3: Recording of real time unilateral RVF after theophylline administration in a patient with cirrhosis.

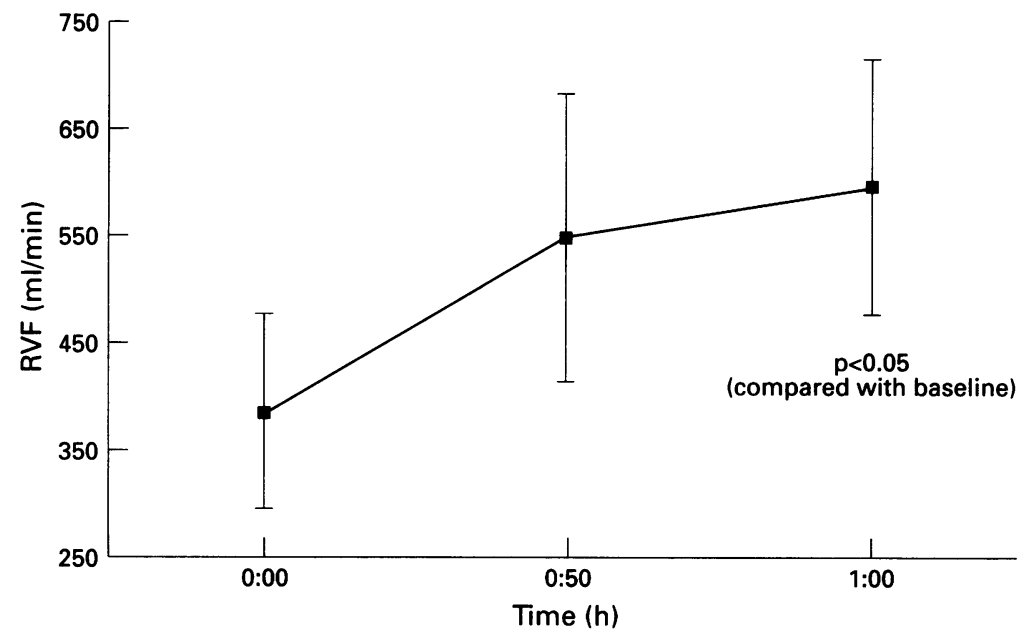

Figure 4: Effect of theophylline on unilateral renal vein flow.

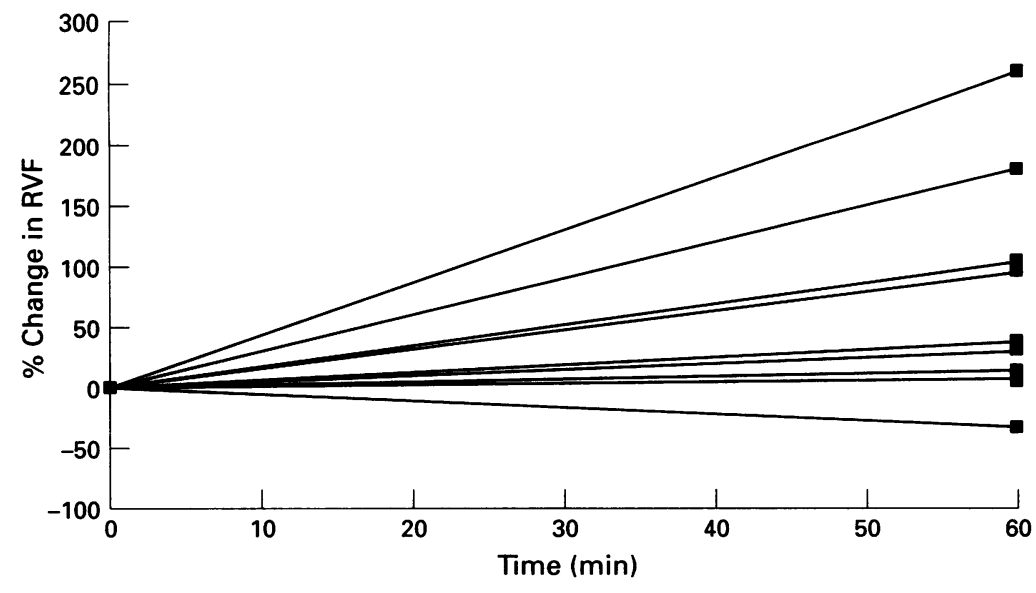

Figure 5: Percentage change in unilateral RVF after theophylline. vasopressors, ${ }^{24}$ and local 'wash out' of adenosine by portal venular flow allows for rapid variations in hepatic arteriolar tone to maintain total hepatic blood flow homeostasis (the 'hepatic artery buffer response'). ${ }^{5}$ These actions are mediated by adenosine- 2 receptors, which may act through adenylate cyclase. ${ }^{25}$ Adenosine-2 receptor activation on endothelial cells may increase nitric oxide production, but adenosine can also act directly on these receptors present on vascular smooth muscle cells to cause vasodilatation. ${ }^{26}$

In the renal circulation adenosine-1 receptors are present particularly on the afferent arterioles. These receptors have a variety of intracellular effects including the inhibition of adenylate cyclase activity resulting in vasoconstriction. ${ }^{25}$ In animal models adenosine causes renal cortical vasoconstriction but preserves medullary perfusion - similar to that which occurs in the kidneys of patients with cirrhosis. ${ }^{27}$ Inhibition of the cellular uptake of adenosine by dipyridamole augments adenosine action. In patients with cirrhosis this causes a further deterioration in renal plasma flow especially in those with increased plasma renin activity. ${ }^{28}$ Therefore adenosine may be responsible for the continued responsiveness of the renal circulation to vasopressors. We measured fasting caffeine values to see if this had any effect upon the action of theophylline. It has previously been recognised that fasting caffeine values are high in patients with cirrhosis and that these values are an indicator of the severity of liver disease. The fasting caffeine values that we found are similar to those which have been previously described in patients with cirrhosis. Normal subjects have fasting caffeine values of approximately $1 \mathrm{mg} / 1 .{ }^{29}$ This shows the difficulty of discounting the effect of plasma caffeine in such patients. Such chronically high concentrations of caffeine may upregulate adenosine receptors. ${ }^{30}$

In this study we have shown that theophylline significantly improves renal perfusion in patients with cirrhosis. We used the reverse thermodilution technique to measure unilateral RVF. This has previously been used in humans and found to correlate very well with the renal plasma flow as determined by para-aminohippuric acid. ${ }^{31}$ It is a safe and rapid method of evaluating total renal blood flow, although its main limitation is its inability to assess the glomerular filtration rate. The increase in RVF occurred independently of any effect on the systemic vasculature and therefore is probably mediated by adenosine- 1 receptor antagonism. The rise in renal blood flow is different from that seen in normal controls in whom a transient rise may be observed followed by a fall in renal plasma flow. ${ }^{32}$ This implies a significant role for adenosine in the renal vascular disturbance of cirrhosis. Previous studies carried out in animals and patients with cirrhosis have indicated that adenosine is most potent as a renal vasoconstrictor in the presence of an activated renin-angiotensin-aldosterone system. It is perhaps surprising that the patients with ascites, and presumably therefore increased 
TABLE III Renal and systemic haemodynamics in controls

\begin{tabular}{llcr}
\hline & Number & Baseline & \multicolumn{1}{c}{60 minutes } \\
\hline HR (bpm) & 4 & $80 \cdot 0(7 \cdot 9)$ & $76 \cdot 8(7 \cdot 0)$ \\
MAP (mm Hg) & 4 & $85(2 \cdot 0)$ & $87 \cdot 2(4 \cdot 1)$ \\
CO (1/min) & 4 & $7 \cdot 4(1 \cdot 4))$ & $7 \cdot 3(1 \cdot 4)$ \\
SVR (dynes-s/cm $\left.{ }^{-5}\right)$ & 4 & $972(162)$ & $1017(172)$ \\
RVF (ml/min) & 4 & $386(191)$ & $352(187)$ \\
\hline
\end{tabular}

Mean (SEM)

TABLE IV Plasma theophylline and caffeine values

\begin{tabular}{lll}
\hline & Theophylline $(m g /)$ & Caffeine $(m g /)$ \\
\hline Baseline & $0.80(0.36)$ & $6.48(1.24)$ \\
30 minutes & $4.03(0.65)$ & - \\
60 minutes & $5.37(0.80)$ & - \\
\hline
\end{tabular}

Mean (SEM).

RAAS activity, had lesser rises in RVF after theophylline. This may be artefactual due to the small numbers of patients studied without ascites. However it may suggest that although adenosine has an important part to play in the renal hypoperfusion, other vasoconstrictors such as endothelin or locally produced prostanoids may be involved in patients with decompensated liver disease.

In addition adenosine may have a minor role in the maintenance of the splanchnic hyperaemia of cirrhosis - the so called 'forward' component of portal hypertension. It is possible that the small effect of theophylline upon HVPG is related to a reduction in splanchnic inflow mediated by adenosine-2 receptor antagonism. However these changes are relatively subtle and this is perhaps why the indirect ICG estimation of total hepatic blood flow did not change significantly. The effect upon AzBF, although significant on paired testing, was also highly variable and was directly related to the plasma concentrations of theophylline, perhaps reflecting the extent of adenosine blockade.

Despite these splanchnic and renal vascular changes no effect was seen on CO or SVR. The increase in heart rate is probably a direct effect of adenosine-1 antagonism on the chronotropic tissues of the heart. ${ }^{43}$ This implies that adenosine does not play a significant part in the peripheral vasodilatation of these patients. This dissociation of the splanchnic and systemic vasodilatation has been noted in animal models of portal hypertension. ${ }^{34}$

The effects we have demonstrated differ from other studies that investigated the effect of methyl xanthines on the haemodynamics of cirrhosis. MacMathuna et al described an improvement in CO and SVR in patients with compensated cirrhosis after theophylline, ${ }^{11}$ and Milani et al found only a $16 \%$ increase in renal blood flow after aminophylline. ${ }^{12}$ Moreau et al did not demonstrate any effect of theophylline upon portal haemodynamics. ${ }^{10}$ However the first two of these studies used the intravenous route of administration and MacMathuna et al described plasma concentrations of $10 \mathrm{mg} / 1 .{ }^{11}$ It is possible that higher plasma values of theophylline than those which we studied had effects beyond that of adenosine antagonism.
Alternatively differing concentrations of adenosine antagonist may result in a differing spectrum of adenosine receptor blockade as the $\mathrm{Kd}$ of adenosine-1 receptors is much lower than that of adenosine- 2 receptors. In the study by Moreau et al intravenous aminiophylline was also used. However at a dose of $3 \mathrm{mg} / \mathrm{kg}$ plasma values of theophylline reached approximately $7 \mathrm{mg} / \mathrm{l}$, similar to those in this study. Although they demonstrated a rise in HR without any change in CO or SVR, no change was noted in AzBF or HVPG. The reasons for these differences are unclear. Certainly fewer patients were studied by Moreau et al at this dose $(n=6)$ and all but one of them were Child's grade C. It may be that if more patients without such severe decompensated liver disease had been studied similar changes in the portal circulation might have been seen.

The lowering of PVR is similar to that seen in animal models. ${ }^{35}$ The role of adenosine in the pulmonary circulation is uncertain. Adenosine vasodilates the pulmonary vasculature in normal subjects. ${ }^{36}$ However in sheep adenosine has been noted to cause pulmonary vasoconstriction possibly through thromboxane A2. ${ }^{37}$ Whether theophylline is acting independently of adenosine antagonism in our patients, or there is an upregulation of adenosine-1 receptors in the pulmonary vasculature in patients with cirrhosis remains uncertain.

In conclusion we have demonstrated that adenosine has a major part to play in the renal circulation of cirrhosis and a lesser role in the maintenance of splanchnic hyperaemia. Antagonism of adenosine receptors by theophylline does not compromise systemic haemodynamics but improves renal blood flow. Such antagonism may also improve sodium excretion, ${ }^{38}$ but this was not investigated in this study. Therapeutically theophylline is not an ideal drug for patients with cirrhosis as it is poorly cleared. ${ }^{17}$ However more specific adenosine-1 receptor antagonists may in the future have a role in the treatment of the renal abnormalities of cirrhosis.

Dr Forrest is funded by Boehringer Mannheim UK. The authors thank Mr R Dawkes for performing the methyl xanthine authors

1 Schrier RW, Arroyo V, Bernardi M, Epstein M, Henriksen JH, Roes J. Peripheral arterial vasodilatation hypothesis: a proposal for the initiation of renal sodium and water a proposal for the initiation of renal sodium and
retention in cirrhosis. Hepatology 1988; 8: 1151-7.

2 Grose RD, Hayes PC. The pathophysiology and pharmacological treatment of portal hypertension. Aliment Pharmacol Ther 1992; 6: 521-40.

3 Whittle BJR. Nitric oxide: the elusive mediator of the hyperdynamic circulation of cirrhosis. Hepatology 1992; 16: $1089-92$.

4 Bruns RF. Adenosine receptors - roles and pharmacology. Ann NY Acad Sci 1990; 603: 211-25.

5 Lautt WW. Mechanism and role of intrinsic regulation of hepatic blood flow - hepatic artery buffer response. Am f Physiol 1985; 249: H549-56.

6 Edlund A, Ohlsen H, Sollevi A. Renal effects of local infusion of adenosine in man. Clin Sci 1994; 87: 143-9.

7 Agmon Y, Dinour D, Brezis M Disparate effects adenosine A1 and A2 recertor adenosine $\mathrm{A} 1$ and $\mathrm{A} 2$ receptor agonists on intrarenal blood fow. Am 7 hysiol 1993 ; 265 . F802-6.

Lee SS, Chilton EL, Pak JM. Adenosine receptor blockade reduces splanchnic hyperaemia in cirrhotic rats. Hepatology 1992; 15: 1107-11.

Cailmail S, Kleber G, Gaudin C, ations in cirrhotic rats. Am $\mathcal{f}$ Physiol 1991; 260: G543-7. 
10 Moreau R, Champigneulle B, Gaudin C, Poo JL, Kleber G, Bacq $\mathrm{Y}$, et al. Effects of theophylline on haemodynamics
and tissue oxygenation in patients with cirrhosis. $\mathscr{f}$ Hepatol 1992; 15: 323-9.

11 MacMathuna $\mathrm{P}$, Vlavianos $\mathrm{P}$, Wendon J, Westaby $\mathrm{D}$, Williams R. Role of adenosine in the haemodynamic disturbances of cirrhosis and portal hypertension. (Abstract) Hepatology 1990; 12: 852.

12 Milani L, Merkel C, Gatta A. Renal effects of aminophylline in hepatic cirrhosis. Eur $\mathcal{f}$ Clin Pharmacol 1984; 24: 757-60.

13 Smits P, Lenders JWM, Thien T. Caffeine and theophylline attenuate adenosine-induced vasodilatation in humans. Clin Pharmacol Ther 1990; 48: 410-8.

14 Fredholm BB. Are methylxanthine effects due to antagonism of endogenous adenosine. Trends Pharmacol Sci $1980 ; 129-32$.

15 Caesar J, Shaldon S, Chiandusi L, Guevara L, Sherlock S. The use of indocyanine green in the measurement of hepatic blood flow and

16 Hayes P, Terrace D, Peaston I, Bouchier I, Redhead D, Brash H. A computerised system for the continuous measurement of azygos blood flow. Gut 1992; 33: 372-4

17 Mangione A, Imhoff TE, Lee RV, Shum LY, Jusko WJ. Pharmacokinetics of theophylline hepatic cirrhosis. Chest 1978; 73: 616-22.

18 Pickard CE, Steward AD, Hartley R, Lucock MD. A rapid HPLC method for monitoring plasma levels of caffeine and theophylline using solid phase extraction. Ann Clin Biochem 1986; 23: 440-3.

19 Forrest EH, Jones AL, Dillon JF, Walker J, Hayes PC. The effect of nitric oxide synthase inhibition on portal pressure 1995; 23: 254-8.

20 Keil JW, Pitts V, Benoit JN, Granger DN, Shepherd AP Reduced vascular sensitivity to norepinephrine in porta hypertensive rats. Am f Physiol 1985; 248: G192-5.

21 Murray BM, Paller MS. Decreased pressor reactivity to angiotensin II in cirrhotic rats. Evidence for post-receptor defect in angiotensin action. Circ Res 1985; 57: 424-31.

22 Hartleb M, Moreau R, Cailmail S, Gaudin C, Lebrec D. Vascular hyporesponsiveness to endothelin 1 in rats with cirrhosis. Gastroenterology 1994; 107: 1085-93.

23 Bernardi M, Santini C, Trevisani F, Baraldini M, Ligabue A, Gasbarrini G. Renal function impairment induced by change in posture in patients with cirrhosis induced by change in posture in pat

24 Lautt WW, Legare DJ. Adenosine modulation of hepatic arterial but not portal venous constriction induced by sympathetic nerves, norepinephrine, angiotensin, and vasopressin in the cat. Can 7 Physiol Phrmacol 1985; 64: 449-54.

25 Londos C, Cooper DMF, Wolff J. Subclasses of external adenosine receptors. Proc Natl Acad Sci 1980; 77 2551-4.

26 Moritoki $\mathrm{H}$, Matugi $\mathrm{T}$, Takase $\mathrm{H}$, Ueda $\mathrm{H}$, Tanioka $A$ Evidence for the involvement of the cyclic GMP in adenosine-induced, age-dependant vasodilatation. $\mathrm{Br} f$ Pharmacol 1990; 100: 569-75.

27 Kew MC, Varma RR, Williams HS, Brunt PW, Hourigan KJ, Sherlock S. Renal and intrarenal blood-flow in cirrhosis of the liver. Lancet 1971; ii: 504-10.

28 Llach J, Gines P, Arroyo V, Salmeron JM, Gines A, Jiminez W, et al. Effect of dipyridamole on the kidney function in cirrhosis. Hepatology 1993; 17: 59-64.

29 Hasegawa M, Yamada S, Hirayama C. Fasting caffeine level in cirrhotic patients: relation to plasma levels of in cirrhotic patients: relation to plasma levels of
catecholamines and renein activity. Hepatology 1989; 10: 973-7.

30 Paul S, Kurunwuna B, Biaggioni I. Caffeine withdrawal apparent heterologous sensitization to adenosine and prostacyclin actions in human platelets. $\mathcal{F}$ Pharmacol Exp Ther 1993; 267: 838-43.

31 Hornych A, Brod J, Slechta V. The measurement of renal venous outflow in man by the local thermodilution method. Nephron $1971 ; 8$ : 17-32.

32 Chasi H, Ranges HA, Goldring W, Smith HW. The control of renal blood flow and glomerular filtration rate in normal man. F Clin Invest 1938; 17: 683 .

33 Daval JL, Nehlig A, Nicolas F. Physiological and pharmacological properties of adenoine: therapeutic pharmacological properties of adeno

34 Um S, Nishida O, Tokubayashi M, Kimura F, et al. Haemodynamic changes after ligation of a major branch of the portal vein in rats: comparison with rats with portal vein constriction. Hepatology 1994; 19: 202-9.

35 Quimby CW, Aviado DM, Schmidt CF. The effects of aminophylline and other xanthines on the pulmonary circulation. F Pharmacol Exp Ther 1958; 122: 396-405.

36 Utterback DB, Staples ED, White SE, Hill JA, Belardinalli $\mathrm{L}$. Basis for the selective reduction of pulmonary vascular resistance in humans during infusion of adenosine. F Appl Physiol 1994; 76: 724-30.

37 Biaggioni I, Landon LS, Enayat N, Robertson D, Newman $\mathrm{JH}$. Adenosine produces pulmonary vasoconstriction in Jheep. Circ Res 1989; 65: 1516-25.

38 Churchill PC, Bidani A. Renal effects of selective adenosine receptor agonists in anaesthetized rats. Am F Physiol 1987; 252: F299-303. 